\title{
Multiscale Analysis of Antarctic Surface Temperature Series by Empirical Mode Decomposition
}

\author{
GUILHEM AUTRET \\ LEGOS, and IRAP, Université de Toulouse, CNRS, Toulouse, France \\ FRÉDÉRIQUE RÉMY \\ LEGOS, Université de Toulouse, CNRS, Toulouse, France \\ SYLVIE ROQUES \\ IRAP, Université de Toulouse, CNRS, Toulouse, France
}

(Manuscript received 28 February 2011, in final form 28 September 2011)

\begin{abstract}
This article illustrates the multiscale nature of the Antarctica climatology. Its variability is analyzed from coastal weather stations climate recordings of the continent, supplying temperature data since 1955. Using empirical mode decomposition, coupled to wavelet analysis, climatological signals are detected of a weak near-8-yr rotating wave that could be the so-called Antarctic Circumpolar Wave.
\end{abstract}

\section{Introduction}

The different climate couplings connecting the Antarctic, the austral system (atmosphere, ocean, and sea ice), and the highest latitudes are poorly known and poorly described until now and must be better understood for conducting realistic studies of the long-term global climate change. In this context, the analysis and the interpretation of the data series on the evolution of physical parameters (atmospheric pressure, temperature, wind velocity, etc.) are essential for better constraining the different couplings and links regulating austral climatology and better describing the natural variability of the Antarctica in order to outline the current climate evolution (Rémy et al. 2002; Monaghan and Bromwich 2008).

In this article, we want to focus on characterizing the Antarctic Circumpolar Wave, one of the most salient manifestations of austral variability. This wave, detected in 1996 by White and Peterson (1996), has so far only

Corresponding author address: Sylvie Roques, Institut de Recherche en Astrophysique et Planétologie, Université de Toulouse, CNRS, 14 avenue Edouard Belin, F-31400 Toulouse, France.

E-mail: sylvie.roques@ast.obs-mip.fr been observed in the atmosphere (temperature and winds), the ocean, and the sea ice (salinity) of the austral system (Connolley 2003). Its intensity seems to be more particularly marked from the 1980s to 1995 and weaker before and after that period. It is known, however, particularly because of these atmospheric and oceanic studies, that it has followed the circumpolar current by flowing along the Atlantic, Indian, and Pacific Oceans over 8-10 years. It exhibits two minima and two maxima, to the extent that the apparent periodicity is 4 years in one location (White and Peterson 1996; White and Chen 2002). The different underlying coupling mechanisms are difficult to identify because the time scales are long compared with the duration of the available observations from space. Moreover, the mechanisms capable of maintaining it are for their own part also quite speculative. Is it due to a local system coupling ocean and atmosphere instabilities, to a passive response of the ocean to atmospheric variability, or to a manifestation or a trigger of the El Niño phenomenon? For the latter hypothesis, the potential links with this climate phenomenon have recently mobilized the concerned scientific community.

The presence of this weak wave on the Antarctic continent had never been detected as yet until the authors' findings were presented. Very few studies exist on the subject because, on the continent, no oceanic data 
TABLE 1. Latitude, longitude, and record duration of each station.

\begin{tabular}{lccc}
\hline \hline \multicolumn{1}{c}{ Station } & Lat & Lon & Record duration \\
\hline Bellingshausen & $62^{\circ} 12^{\prime} \mathrm{S}$ & $58^{\circ} 58^{\prime} \mathrm{W}$ & $63 \mathrm{yr}$ \\
Casey & $66^{\circ} 17^{\prime} \mathrm{S}$ & $110^{\circ} 32^{\prime} \mathrm{E}$ & $53 \mathrm{yr}$ \\
Dumont d'Urville & $66^{\circ} 40^{\prime} \mathrm{S}$ & $140^{\circ} 00^{\prime} \mathrm{E}$ & $54 \mathrm{yr}$ \\
Faraday-Vernadsky & $65^{\circ} 15^{\prime} \mathrm{S}$ & $64^{\circ} 16^{\prime} \mathrm{W}$ & $66 \mathrm{yr}$ \\
Halley & $75^{\circ} 35^{\prime} \mathrm{S}$ & $26^{\circ} 30^{\prime} \mathrm{W}$ & $53 \mathrm{yr}$ \\
Mawson & $67^{\circ} 36^{\prime} \mathrm{S}$ & $62^{\circ} 52^{\prime} \mathrm{E}$ & $56 \mathrm{yr}$ \\
Mirny & $66^{\circ} 33^{\prime} \mathrm{S}$ & $93^{\circ} 01^{\prime} \mathrm{E}$ & $54 \mathrm{yr}$ \\
Molodezhnaya & $67^{\circ} 40^{\prime} \mathrm{S}$ & $45^{\circ} 51^{\prime} \mathrm{E}$ & $36.5 \mathrm{yr}$ \\
Novolazarevskaya & $70^{\circ} 46^{\prime} \mathrm{S}$ & $11^{\circ} 50^{\prime} \mathrm{E}$ & $49 \mathrm{yr}$ \\
Scott Base & $77^{\circ} 51^{\prime} \mathrm{S}$ & $166^{\circ} 46^{\prime} \mathrm{E}$ & $53 \mathrm{yr}$ \\
\hline
\end{tabular}

(e.g., surface temperature) have been available globally since the 1980s. Besides, the weather models are far less constrained on Antarctica than they ought to be, and data assimilation should be improved (Brun et al. 2011). Thus, to date, no model has proven capable of generating it correctly, to the extent that the primordial role of the Antarctic in the climate variability is still difficult to ascertain.

At the moment, the complementarity of modeling and remote sensing provides an enormous breakthrough in the knowledge of the mechanism and the evolution of the ice sheet. Unfortunately, temporal series have only been available since the 1980s as regards radiometry and only since 1991 with European Remote Sensing Satellite-1 (ERS-1). They are hence relatively short with respect to the time scales governing the natural fluctuations of the polar climate (Rémy et al. 2002). Our objective is to provide the best possible description of the natural variability of the Antarctic weather report by using the longest available time series. We use ground-based data collected from 10 coastal stations. These stations, distributed in a relatively regular way along the coast around the continent, have been supplying temperature data since the 1950s. In order of decreasing longitude, there are as follows: Scott $\left(166^{\circ} 46^{\prime} \mathrm{E}\right)$, Dumont d'Urville $\left(140^{\circ} 00^{\prime} \mathrm{E}\right)$, Casey $\left(110^{\circ} 32^{\prime} \mathrm{E}\right)$, Mirny $\left(93^{\circ} 01^{\prime} \mathrm{E}\right)$, Mawson $\left(62^{\circ} 52^{\prime} \mathrm{E}\right)$, Molodezhnaya $\left(45^{\circ} 51^{\prime} \mathrm{E}\right)$, Novolazarevskaya $\left(11^{\circ} 50^{\prime} \mathrm{E}\right)$, Halley $\left(26^{\circ} 30^{\prime} \mathrm{W}\right)$, Bellingshausen $\left(58^{\circ} 58^{\prime} \mathrm{W}\right)$, and Faraday $\left(64^{\circ} 16^{\prime} \mathrm{W}\right)$ (see Table 1 and Fig. 1).

\section{Antarctic data and empirical mode decomposition}

In the problem we address, the aim is to obtain very fine measurements of the oscillation mode frequencies that may point out nonstationary weak signals, as well as the set of the quantities characterizing these modes (amplitudes, phases, and modulations). It is essential also to measure their duration and energy.

Until now, the approaches used for studying the fullness of these ground-based signals have relied on statistical

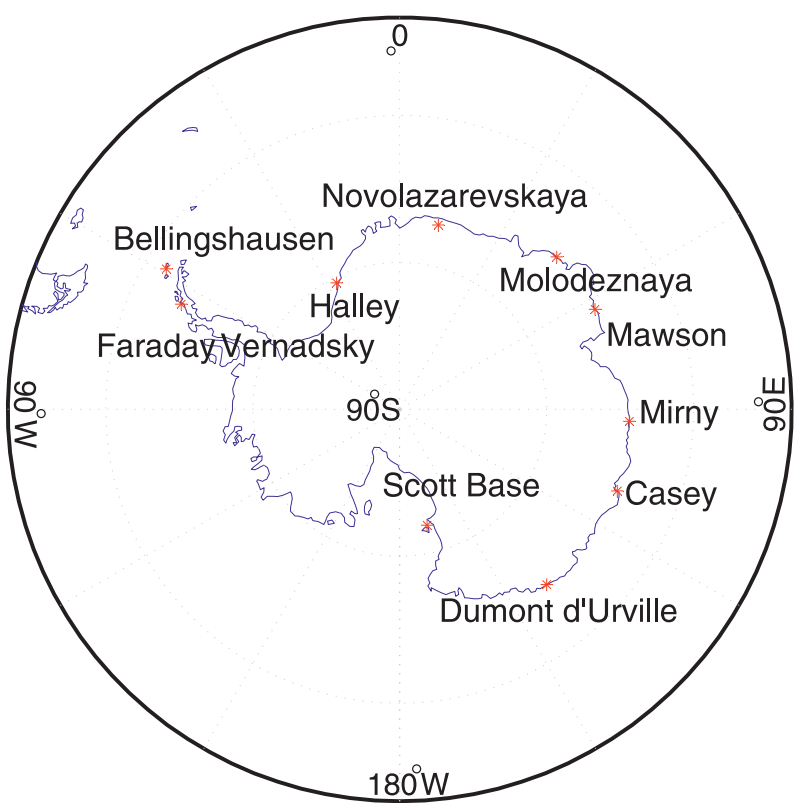

FIG. 1. Location of the stations.

or parametric surveys (Jacka et al. 2004). A period close to 4 years has been studied without, however, being able to prove its rotating character. Tools accounting for nonstationary and delocalized phenomena, highlighting the explicit role of time, are nevertheless capable of providing numerous additional pieces of information (Sonechkin and Datsenko 2000). In this context, we present below the results obtained by matching pursuit as suggested by Mallat and Zhang (1993), and then we offer an original adaptation of empirical mode decomposition (EMD; Huang et al. 1998), which by its adaptive character enables us to uncover the expected behavior. Such methodologies have already been described and applied by Duffy (2004), Thiebaut and Roques (2005), and Veltcheva and Soares (2007) for meteorological, astronomical, or oceanic datasets.

\section{a. The failure of traditional and not so traditional methods}

The principle of the matching pursuit method includes searching for, in a redundant dictionary of oscillating functions, a subset to come as close as possible to the signal. The method is adaptive to the extent that the selection of this subset of functions is performed as decomposition unfurls. It is then possible to know which frequencies are predominant and when they appear in and disappear from the signal. For instance, with reference to Fig. 2, the horizontal elements are characteristic of the coherent structures of the signal: their long lifetime, associated with a well-localized value of the frequency, indicates a durable oscillation whose times of appearance 


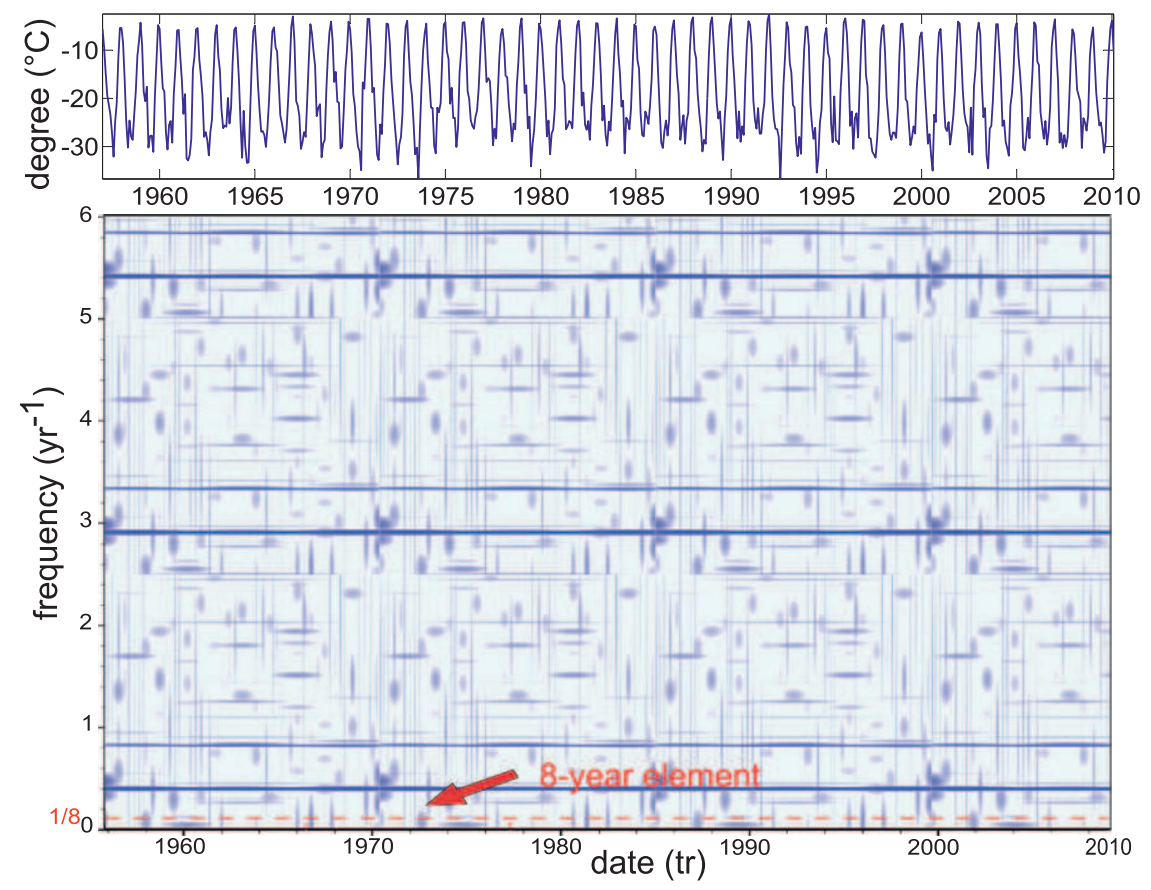

FIG. 2. Matching pursuit decomposition of the monthly temperature variations of the Halley station. (top) The signal (abscissa is temporal samples in year; ordinate is temperature in degrees Celsius). (bottom) The time-frequency decomposition (abscissa is temporal samples in yr; ordinate is temporal frequency in $\mathrm{yr}^{-1}$ ) representing the most coherent structures of the signal: these elements appear as long (in time) pictures in the time-frequency plane (horizontal elements). An 8-yr element appears at the bottom of the diagram, with approximately 7-yr lifetime (red arrow) but short time.

and disappearance are identified precisely. This enables us to identify the annual and seasonal variations ( 1 year and 6 months) and some of their harmonics. Conversely, because the vertical elements are precisely localized in time and unfold over a wide frequency range, they represent sudden rupture-type events (characteristic of, e.g., unstable winters). A simple filtering keeping only the longtime elements allows us to eliminate the information corresponding to noise or abrupt changes.

The result presented at the Halley station (Fig. 2) is the only one that enables an 8 -yr periodicity component, whose energy is approximately 100 times lower than that representing the seasonal variations, to be revealed. This detection difficulty can be explained by the absence, in the dictionary of functions used, of a waveform adapted to such a low-energy signal. It is also the reason why it seems necessary to implement an adaptive multiscale decomposition, which should make it possible to highlight the sought wave.

\section{b. Empirical mode decomposition and wavelets}

The EMD developed by Huang et al. (1998) can perform self-adaptive decomposition on the basis of nonlinear functions extracted from the signal itself (and not predetermined as for matching pursuit). The EMD is the base of the so-called Hilbert-Huang transform, which includes a Hilbert spectral analysis and an instantaneous frequency computation. Each of the components has a physical meaning and reveals important characteristics of the signal. In its principle, EMD enables us to identify the time scales revealing physical characteristics of the studied signal and to decompose it into intrinsic modes via a sifting process for isolating the different regimes. This sifting process consists of considering oscillations of the signal between two consecutive extrema and defining the corresponding local detail. The procedure can be applied on the residual consisting of all local trends, and constitutive components of the signal can therefore be iteratively extracted. Huang et al. (1998) compare their results with those obtained by methods founded on decompositions into wavelets or Gabor transforms and show that the suggested method can be compared to time-dependent self-adaptive nonlinear filtering.

The EMD of the series of temperature in the Halley station is represented in Fig. 3. For this station, like all others, seven modes are sufficient for decomposing the signal. Their interpretation is immediate: the first mode 


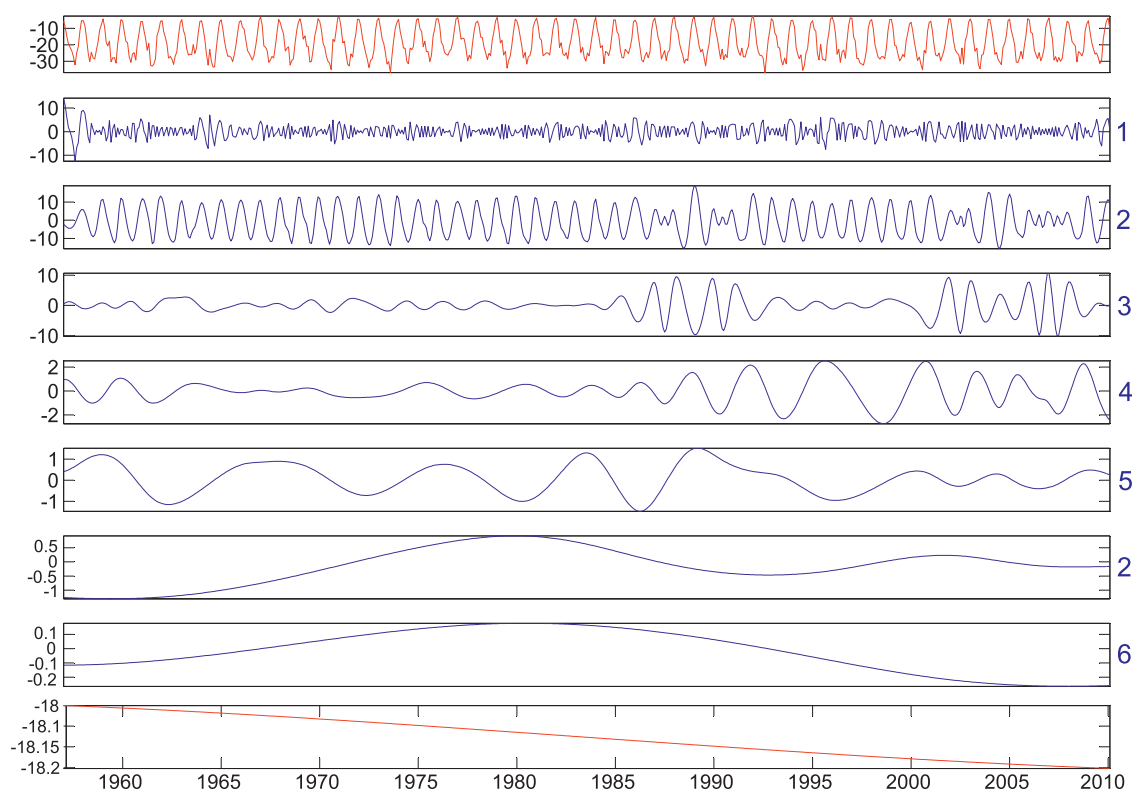

FIG. 3. EMD of the temperature data of the Halley station. (top)-(bottom) The signal (in red), the seven modes (in blue), and the residue (in red). The abscissa is the year. The ordinate shows the temperature amplitude of the mode.

represents the quasi-monthly weather disturbances. The second one represents the seasonal cycles. The third one can be characteristic of the oceanic or atmospheric influences. The fourth one is a quasi-4-yr cycle also observed in spatial oceanographic data. Both latter modes are quite energetic and may probably be capable of altering the analysis of the trends derived from in situ or satellite data. The fifth mode contains the 8-yr mode we look for, characteristic of a previously observed wave (in the following, we will use this mode to better characterize the circumpolar wave). The less energetic sixth and seventh modes are probably connected to greater magnitude fluctuation, which ought to be described and linked with austral climatology at a later stage.

For all of the stations, the results obtained are similar to those presented in Fig. 3. Mode 5 is systematically characteristic of a nonstationary 8-yr-period wave, which has an amplitude 10 times smaller than that of the original signal. Note in passing that the amplitude of this mode is important before 1995 and decreases after. Its degree of nonstationarity can be assessed by its Hilbert transform (Huang et al. 1998), presented in Fig. 4, which does confirm the temporal modulation of this wave observed by oceanographers. A later step will include connecting it to austral variability.

Because EMD is able to project the original signal over relevant frequency bandwidths, it then seems important to screen these various modalities via wavelet analysis, so as to grasp the energy distribution of the modes and their modulations. Modes 5 (8 yr) and 4 (4 yr) collected from all the stations have hence been decomposed on the basis of Paul wavelets (Torrence and Compo 1998) (Fig. 5). This analysis enables us to determine a global wavelet spectrum for each mode. The latter provides access to an average frequency directly and enables us to analyze the phases of this transform so as to detect a rotating wave.

A median wavelet spectrum, calculated with the wavelet spectra of the whole mode 5 (mode 4 ) of each station, presents its maximum at the abscissa of $7.8 \mathrm{yr}$ (3.9 yr). This allows us to identify the 8 -yr wave and its

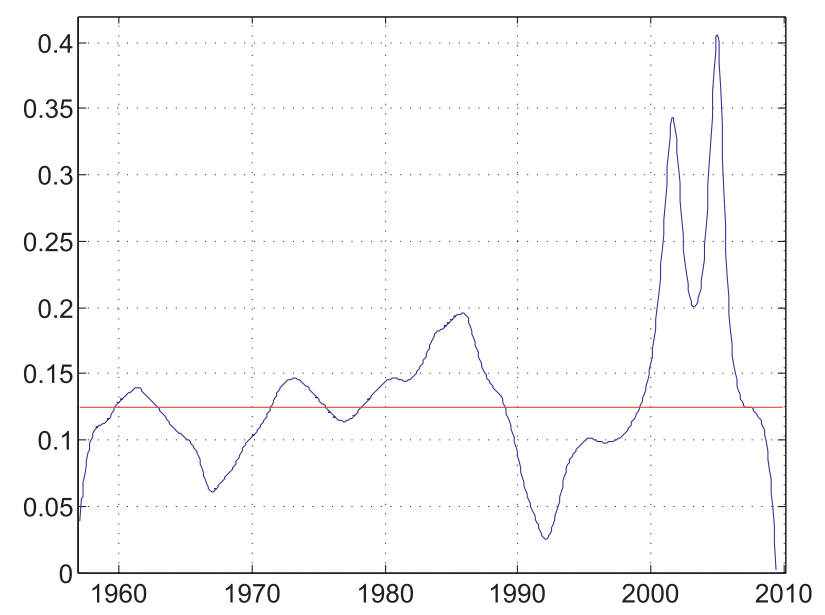

FIG. 4. Hilbert spectrum of mode 5 of Halley temperature data. The abscissa is the year. The ordinate is the frequency in $\mathrm{yr}^{-1}$. An 8-yr period stationary signal is symbolized by the red horizontal line. 

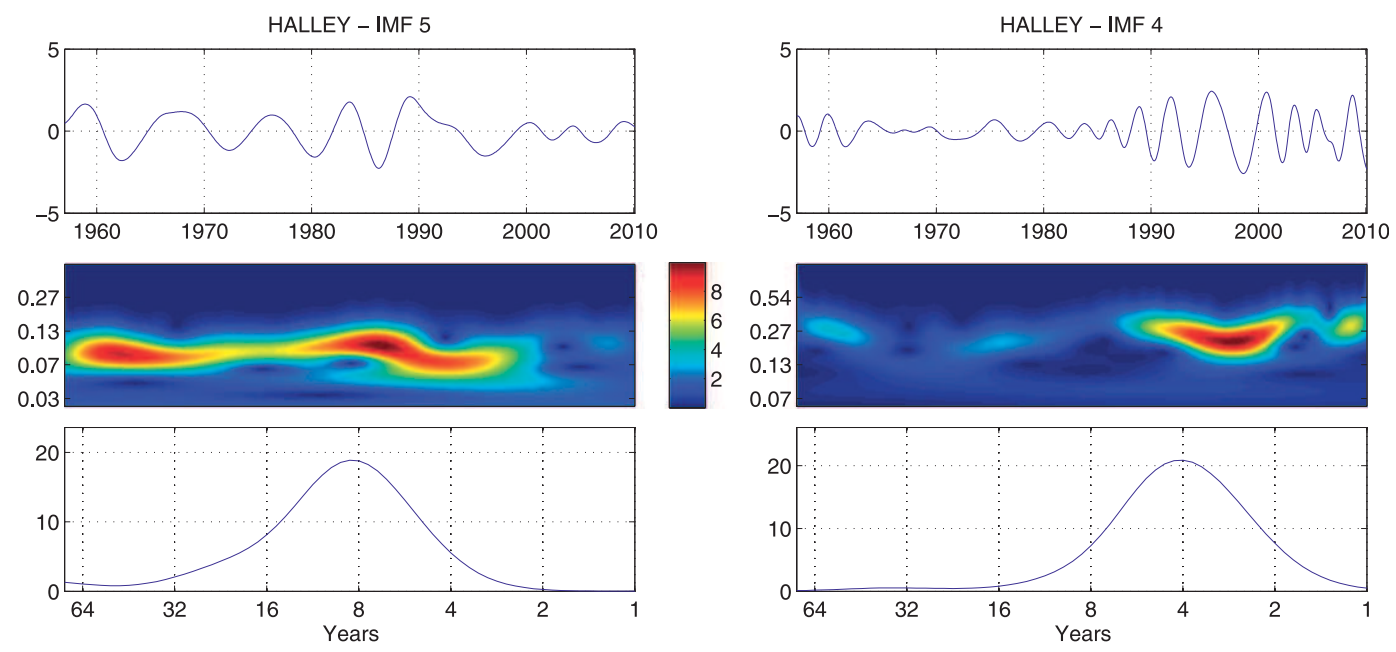

FIG. 5. (top)-(bottom) Mode, wavelet power spectrum $\left({ }^{\circ} \mathrm{C}^{2}\right)$, and global wavelet spectrum for modes (left) 5 and (right) 4 .

4-yr apparent periodicity. In Fig. 6, the instantaneous phase of modes 5 of all the stations are represented after linear interpolation. The finding confirms the idea of a revolving wave, because the former indeed corresponds both to an 8-yr wave velocity and to the geographical position of each station. To confirm this result, we studied the imaginary part of the wavelet transform of the relevant mode by considering it at the longitude of the corresponding station (Fig. 7). The succession of the maxima and of the minima indeed confirms the fact that this wave rotates, and the slope of the straight lines connecting each maximum (or minimum) for each station easily gives the rotational speed (see Fig. 7).

This wave should correspond to the so-called Antarctic Circumpolar Wave. Indeed, we see on most of the stations (Fig. 7) that, in the 1970s-1990s, this intensity corresponds to a period when this wave was known to be particularly strong. The fact that the modulation is more visible on many stations of the Indian Ocean may have several reasons. Leaving purely numerical explanation aside (e.g., less noise-corrupted data than anywhere else or better still adapted methodology in such a case), the cause can be seen in the behavior of the austral system and this wave. As explained above, the circumpolar wave can be detected on the Southern Ocean through anomalies of temperature and sea height, atmospheric pressure, and extent of the sea ice. Still, the anomaly of the sea ice extents-difficult to understand because sea ice totally disappears during the austral summer (a memory effect from one winter to the next seems to be the key) - is marked more strongly in the Indian Ocean (from $20^{\circ}$ to $100^{\circ} \mathrm{E}$ ), contrary to the other anomalies, which are marked more strongly in the Pacific and Atlantic Oceans (Gille 2002; White et al.
2004). Sea ice could play a particular role in the mechanisms of this wave and sporadically transmit the heat signal over the continent.

\section{Conclusions: What new information is in the climatology?}

When perusing Antarctic temperature data, it appears a temporal variability of different periods and modulations that a clear 8-yr signal can be observed in the fifth mode, which can be found on all the stations. It seems that the signature of the detected wave could be the

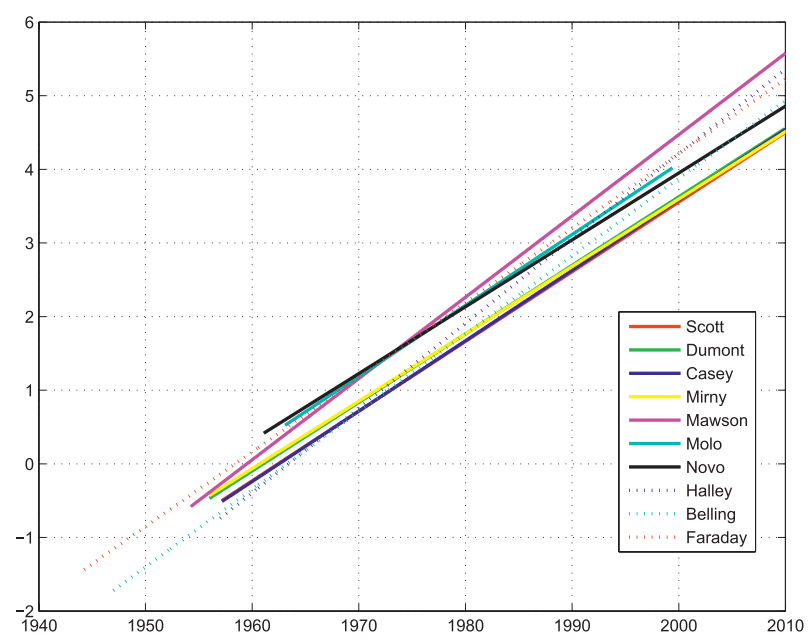

FIG. 6. Instantaneous phases of the wavelet transforms of mode 5 $(8 \mathrm{yr})$. For clarity, these phases are unwrapped and not represented $\bmod (2 \pi)$. The abscissa is the year. The ordinate is the number of revolutions around Antarctica. One can check that one revolution lasts approximately $8 \mathrm{yr}$. 


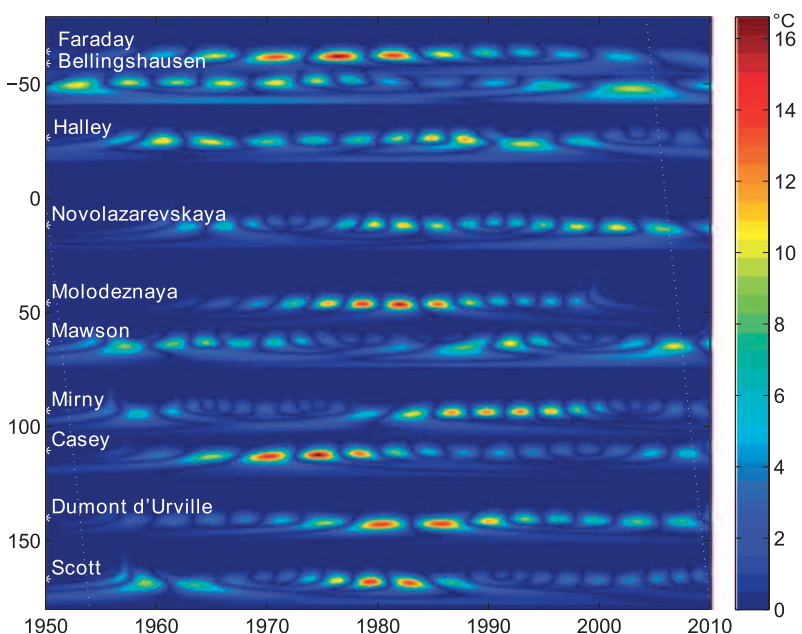

FIG. 7. Phases of the wavelet transforms of mode 5 ( $8 \mathrm{yr}$ ) for all stations. The abscissa is the year. The ordinate is the longitude of the station. The color scale is the wavelet spectrum (imaginary part).

Antarctic Circumpolar Wave. Much work remains to be done on the phases relations to understand how this wave moves, in particular by combining several modes (modes 4 and 5). Moreover, the phases presented in Fig. 6 have been adjusted linearly. Their nonlinear character would suggest that the center of this rotating wave would also move over the continent. Answering this question requires a number of modeling processes currently in progress.

Thus, going by these preliminary works, it seems that the Antarctic Circumpolar Wave is readily detectable on the continent based on these data with the used methodology. It also seems that relying on such methodology may enable us to assert that the wave is more particularly noticeable in certain coast sectors of Antarctica and hence provides us with clues to better understand its propagation and causes.

A modulation that might correspond to the oceanographic observations can also be found at certain stations. The causes should be sought in the geographical situation of the stations, which may be in zones where interactions between the Southern Ocean and the continent are more intense than anywhere else. This may constitute a means for grasping some of the climatic mechanisms of this region.

Acknowledgments. The data have been kindly supplied by the British Antarctic Survey (United Kingdom) and are available online (at http://www.antarctica.ac.uk/ met/gjma/). The authors thank Gerhard Krinner from LGGE/CNRS for his helpful comments.

\section{REFERENCES}

Brun, E., and Coauthors, 2011: Snow/atmosphere coupled simulation at Dome C, Antarctica. J. Glaciol., 57, 721-736, doi:10.3189/002214311797409794.

Connolley, W. M., 2003: Long-term variation of the Antarctic Circumpolar Wave. J. Geophys. Res., 108, 8076, doi:10.1029/ 2000JC000380.

Duffy, D. G., 2004: The application of Hilbert-Huang transforms to meteorological datasets. J. Atmos. Oceanic Technol., 21, 599-611.

Gille, S. T., 2002: Warming of the Southern Ocean since the 1950s Science, 295, 1275-1277, doi:10.1126/science.1065863.

Huang, N. E., and Coauthors, 1998: The empirical mode decomposition and the Hilbert spectrum for nonlinear and non-stationary time series analysis. Proc. Roy. Soc. London, 454, 903-995, doi:10.1098/rspa.1998.0193.

Jacka, T. H., W. F. Budd, and A. Holder, 2004: A further assessment of surface temperature changes at stations in the Antarctic and Southern Ocean, 1949-2002. Ann. Glaciol., 39, 331-338, doi:10.3189/172756404781813907.

Mallat, S. G., and Z. Zhang, 1993: Matching pursuits with timefrequency dictionaries. IEEE Trans. Signal Process., 41, 3397-3415, doi:10.1109/78.258082.

Monaghan, A. J., and D. H. Bromwich, 2008: Advances in describing recent Antarctic climate variability. Bull. Amer. Meteor. Soc., 89, 1295-1306.

Rémy, F., L. Testut, and B. Legrésy, 2002: Random fluctuations of snow accumulation over Antarctica and their relation to sea level change. Climate Dyn., 19, 267-276, doi:10.1007/s00382002-0226-Z

Sonechkin, D. M., and N. M. Datsenko, 2000: Wavelet analysis of nonstationary and chaotic time series with an application to the climate change problem. Pure Appl. Geophys., 157, 653-677, doi:10.1007/PL00001113.

Thiebaut, C., and S. Roques, 2005: Time-scale and time-frequency analyses of irregularly sampled astronomical time series. EURASIP J. Adv. Signal Process., 2005, 2486-2499, doi:10.1155/ASP.2005.2486

Torrence, C., and G. P. Compo, 1998: A practical guide to wavelet analysis. Bull. Amer. Meteor. Soc., 79, 61-78.

Veltcheva, A. D., and C. G. Soares, 2007: Analysis of abnormal wave records by the Hilbert-Huang transform method. J. Atmos. Oceanic Technol., 24, 1678-1689.

White, W. B., and R. G. Peterson, 1996: An Antarctic circumpolar wave in surface pressure, wind, temperature and sea-ice extent. Nature, 380, 699-702, doi:10.1038/380699a0.

_ , and S. C. Chen, 2002: Thermodynamic mechanisms responsible for the tropospheric response to SST anomalies in the Antarctic Circumpolar Wave. J. Climate, 15, 2577-2596. , P. Gloersen, and I. Simmonds, 2004: Tropospheric response in the Antarctic Circumpolar Wave along the sea ice edge around Antarctica. J. Climate, 17, 2765-2779. 